activity in man. Many other factors including the incidence of side effects will determine the therapeutic value of these compounds. However, exploratory clinical study of selected members of this series has produced some interesting results.

We thank Dr. H. J. Barber and Dr. R. Wien for the constructive interest they have taken in this work.

L. Bretherick

G. E. LEE

E. LUNT

W. R. WRAGG

Chemical Research Laboratories.

N. D. EDGE

Biological Research Laboratories,

May and Baker, Ltd.,

Dagenham. Nov. 10.

${ }^{1}$ Lee, G. E., Wragg, W. R., Corne, S. J., Edge, N. D., and Reading H. W., Nature, 181, 1717 (1958). Corne, S. J., and Edge, N. D. Brit. $\dot{J}$. Pharmacol, 13,339 (1958). The independent discovery of the ganglion-blocking activity of $i: 2: 2: 6: 6$-pentamethylpiperidine A., and Young, E. H. P., Nature, 181, 1397 (1958). Spinks, A. Young, E. H. P., Farrington, J. A., and Dunlop, D., Brit. $J$. Pharmacol., 13, 501 (1958).

${ }^{2}$ Harington, M., Kincaid-Smith, P., and Milne, M. D., Lancet, ii, 6 (1958).

${ }^{3}$ Gyermek, L., and Nádor, K., J. Pharm. Pharmacol., 8, 209 (1957).

4 Vaylor, R. F., J. Chem. Soc., 1106 (1947).

\section{Localization of $\beta$-Glucuronidase in Normal and Cancer Cells}

Ir has been shown by Walker ${ }^{1}$ that in a mouse. liver homogenate in isotonic sucrose solution by far the greater part of the $\beta$-glucuronidase activity sediments in the cytoplasmic granules (mitochondria and microsomes). It was concluded that little, if any, of the enzyme is present in the nuclei or free in the cytoplasm. This was also true of rapidly growing or regenerating liver. Within the granules the enzyme displayed only fractional activity due to its inacces. sibility to substrate. In these respects $\beta$-glucuronidase, in rat liver at least, resembles a number of hydrolytic enzymes, which, it has been suggested, are enclosed together within a special type of subcellular particle, the lysosome ${ }^{2}$.

Levvy ${ }^{3}$ has shown that $\beta$-glucuronidase is powerfully inhibited by saccharo-1:4-lactone which causes marked and specific inhibition at concentrations of the order of micromoles. This inhibitor has been employed by oral administration to arrest liberation in the bladder of carcinogens from their glucuronides by urinary 3-glucuronidase ${ }^{4}$. Because of its location within the granules in liver cells it has been suggested ${ }^{2,4}$ that $\beta$-glucuronidase is virtually inactive in healthy tissues and only displays its action when free in body fluids like urine.

It was considered that other tissues might display a pattern of intracellular distribution different from that in liver. Results for mouse kidney and $S 37$ subcutaneous tumours compared with those for liver are shown in Table 1. In the scheme of fractionation adopted, in the case of liver ${ }^{1}$, fraction I

Table 1. INTRACELLULAR DISTRIBUTION OF $\beta$-GLUCURONIDASE IN VARIOUS MOUSE TISSUES

Tissues were homogenized in $0.25 M$ sucrose in a glass homogenizer (1,500 rev./min.). Fractionation was carried out as described by Hogeboom (ref. 9). Results are expressed as a percentage of the total activity of the homogenate, all assays being done in presence of 0.1 per cent 'Triton X-100' (ref. 1). In columns $A$, the tissue was homogenized for $1 \mathrm{~min}$. before fractionation. In column $B$, fraction I was separated at intervals and rehomogenized, the for further fractionation.

Fraction I Fraction II Fraction III (A) Kidney

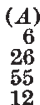

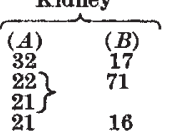

$S 37$ Tumour
$\begin{array}{cc}(A) & (B) \\ 23 & 11 \\ 15 \\ 13 \\ 41\end{array} \quad \begin{gathered}22 \\ 57\end{gathered}$

comprises nuclei and unbroken cells, whereas fractions II and III contain the cytoplasmic granules, and fraction IV unsedimentable enzyme in the cytoplasm. From the work of Straus ${ }^{5}$ it would appear that fractions $I$ and II in the case of kidney may also contain 'droplets' that possess $\beta$-glucuronidase activity.

Under similar conditions of homogenization, a larger proportion of the enzyme is found free in the cytoplasm of kidney and tumour than in that of liver. Moreover, both kidney and tumour differ from liver in their rate of breakdown in $0.25 M$ sucrose, as can be seen from the much larger proportion of the enzyme remaining in fraction $\mathrm{I}$ after homogenizing for $1 \mathrm{~min}$. Prolonged homogenization of both tissues reduces the percentage activity in fraction $I$ to values approaching those for liver, but fractions II and III also fall in activity, indicating breakdown of the particles. If fraction $I$ is repeatedly removed and rehomogenized separately for short periods, there is a marked difference in behaviour between the kidney and tumour preparations. In the case of kidney, the bulk of the enzyme then passes into fractions II and III, and it is evident that fraction IV of the original homogenate is almost entirely derived from the particles. The tumour, in contrast to the normal tissues, shows equally rapid liberation of enzyme into both the cytoplasmic particles and the cytoplasm, and it is concluded that about half the enzyme in the tumour cells is initially free in the cytoplasm. In the tumour the total $\beta$-glucuronidase activity is high, being comparable with that of liver and kidney ${ }^{6}$.

It has been reported that much of the $\beta$-glucuronidase activity in rat spleen is free in the cytoplasm? and that feeding azo dyes to rats causes the release of a very small proportion of the enzyme from the cytoplasmic granules in rat liver ${ }^{8}$.

J. CONCHTE

Rowett Research Institute,

G. A. Levvy

Bucksburn, Aberdeen.

1 Walker, P. G., Biochem. J., 51, 223 (1952).

2 Duve, C. de, Pressman, B. C., Gianetto, R., Wattiaux, R., and Appelmans, F., Biochem. J., 60, 604 (1955).

3 Levvy, G. A., Biochem. J., 52, 464 (1952).

Boyland, E., Brit. Med. Bull., 14, 153 (1958).

Straus, W., J. Biophys. Biochem. Cytol., 2, 513 (1956).

- Conchie, J., and Levvy, G. A., Brit. J. Cancer, 11, 487 (1957).

'Duve, C. de, 'Subcellular Particles', 128 (American Physiol. Soc. Washington, D.C., 1959).

${ }^{8}$ Deckers-Passau, L., Maisin, J., and Duve, C. de, Acta Vnio Int. contra Cancrum, 13, 822 (1957).

'Hogeboom, G. H., 'Methods in Enzymology', 1, 16 (Academic Press, New York, 1955).

\section{Enzymic Reduction of $\alpha$-Aminoadipic Acid by Yeast Enzyme}

RECENT work in this laboratory demonstrated that, with the whole cells of Torulopsis utilis and baker's yeast, $\alpha$-aminoadipic acid is converted to lysine to an appreciable extent ${ }^{1}$ and that it has a primary role for lysine biosynthesis in this organism, as inferred earlier by Strassman and Weinhouse ${ }^{2}$. Enzymic conversion of $\alpha$-aminoadipic acid to lysine has so far been supposed to occur via $\alpha$-aminoadipic acid- $\delta$-semialdehyde, which actually has been shown to be an oxidation product of hexahomoserine catalysed by mould enzyme ${ }^{3}$; but no evidence for the enzymic reduction of $\alpha$-aminoadipic acid to its semialdehyde has hitherto been presented. The present communication reports the enzymic reduction of $\alpha$-aminoadipic acid to an intermediary substance which is easily converted to dehydropiperidine-2-carboxylic acid, a cyclized form of $\alpha$-aminoadipic acid- $\delta$-semialdehyde.

The enzyme solution was prepared by grinding a frozen cell paste of baker's yeast (or T. utilis) with glass wool powder and extracting with $0.05 \mathrm{M}$ potassium 